\title{
Tools to Use in the Analysis of Potential New Market Expansion
}

\section{Haron $\mathrm{AJ}^{*}$}

Higher Colleges of Technology, Sharjah, United Arab Emirates

\begin{abstract}
Each year, many entrepreneurial, growing, and developing companies contemplate international enlargement as a marketing and growth strategy. When developing a strategic blueprint to launch an international business program, developing companies and their consultants must always ponder the potential barriers and modifications they might need to make to their products and services. In this paper, we put forward four analysis tools, which can help companies minimize any negative impact.
\end{abstract}

Keywords: Analysis tools; Ansoff's matrix; Macro-Environmental analysis; Porter's five-forces concept; Key/critical success factors; Hertzberg's motivation theory; Maslow's hierarchy of needs; McGregor's theory $\mathrm{x}$ - theory $\mathrm{y}$

\section{Introduction}

Each year, many entrepreneurial, growing, and developing companies contemplate international enlargement as a marketing and growth strategy [1]. When developing a strategic blueprint to launch an international business program, developing companies and their consultants must always ponder the potential barriers and modifications they might need to make to their products and services. In this paper, we put forward four analysis tools, which can help companies minimize any negative impact. These tools include the following:

\section{Ansoff's matrix \\ When companies are focused on growth, some of the most useful tools to develop strategies for growth is the four quadrants of Ansoff's matrix: market development, market penetration, product diversification and development. Watts et al. argued that because of limitations, it has been recommended that certain strategic substitutes are typically more suitable for smaller firms, namely those that circumvent direct competition with larger firms and that include the development of close customer associations and product adaptation. In the language of Ansoff's Matrix, it has been recommended that for SMEs the most suitable growth strategies are consequently market development and product development [2]. This is the advantage of using Ansoff's matrix, granted it is from the perspective of SMEs only, however, we can see what value this tool brings to the table.}

\section{Macro-environmental analysis}

Macro-Environmental analysis, such as STEP, PEST, SERF and PESTLE help companies deal with many seen and unforeseen challenges by obliging the company to analyze the macro environment of the host country, this tool will help detect and rectify the following but-not-limited-to issues: economic trends, political stability, currency exchange rates, religious considerations, dietary customers and restrictions, lifestyle issues, foreign investment and approval procedures, restrictions on termination and nonrenewal (where applicable), regulatory requirements, access to resources and raw materials, availability of transportation and communication channels, labor and employment laws technology transfer regulations, language and cultural differences, access to affordable capital and suitable sites for the development of units, governmental assistance programs, customs laws and import restrictions, tax laws and applicable treaties, repatriation and immigration laws, trademark registration requirements, availability and protection policies, costs and methods for dispute resolution, agency laws and availability of appropriate media for marketing efforts [3].

\section{Porter's five-forces concept}

Porter's five-forces concept, is a great tool for analyzing the competitive environment of the host country especially with regards to the amount of pressure these forces will be putting on our company, the greater the forces the less profits our company will potentially make [4].

\section{Key/critical success factors}

Key/critical success factors, is another tool to help us understand our abilities and limitations, by looking at our key success factors, we can determine if our organization has the what it takes to take on potential competitors in the new market. This will help us realize if we have all or any of the following: Expertise in a particular technology, scale economies, experience curve benefits, high capacity utilization, and strong network of wholesale distributors, brand-building skills, and convenient retail locations [5].

\section{Three Tools for Effective Involvement and Management of Human Resources}

The three tools we would recommend using to maximize the involvement of our people are:

\section{Hertzberg's motivation theory}

According to Furnham et al., Herzberg's seminal two-factor theory of motivation assumed that satisfaction and dissatisfaction were not two opposite extremes of the same variety, but two separate objects caused by fairly different aspects of work - these were branded as "hygiene factors" and "motivators". Hygiene factors are characterized as extrinsic mechanisms of job design that add to employee dissatisfaction if they

*Corresponding author: Haron AJ, Higher Colleges of Technology, Sharjah, United Arab Emirates, Tel: +971 2681 4600; E-mail: abbottjharon@hotmail.com

Receved December 05, 2014; Accepted January 07, 2015; Published January 16, 2015

Citation: Haron AJ (2015) Tools to Use in the Analysis of Potential New Market Expansion. J Entrepren Organiz Manag 4: 126 doi: 10.4172/2169-026X.1000126

Copyright: ( 2015 Haron AJ. This is an open-access article distributed under the terms of the Creative Commons Attribution License, which permits unrestricted use, distribution, and reproduction in any medium, provided the original author and source are credited. 
are not met. Examples include management, working environments, company policies, pay, and relations with coworkers. Motivators, nevertheless, are intrinsic to the job itself and include facets such as accomplishment, growth, accountability, and recognition. This should give us insight into how to motivate our employees to perform [6].

\section{Maslow's hierarchy of needs}

Maslow's hierarchy of needs is another useful tool to get the most out of our human resource, the hierarchy includes, 1 . Shelter, food, air, water, 2. Safety, security, 3. Love and belonging, 4 . Self-esteem and 5. Self actualization. Many companies assume that money motivates all employees. Carpenito-Moyet proposes that motivators for employees may be different depending on where the employee is on Maslow's hierarchy. The current financial and economic crisis, for which there is no end in sight, has attracted prospective employees from varied levels of Maslow's hierarchy. This will make it much more challenging to find uniformly ways to motivate them; it means they will have to be treated and compensated based on their level on the hierarchy [7].

\section{McGregor's theory $x$ - theory $y$}

Aaccording to Weisbord, since Douglas McGregor's breakthrough book, The Human Side of Enterprise (1960), transformed the path of executive thinking and practice. Using this tool will help us question some of the essential conventions about human behavior in organizations, and help us outline a new role for our managers: instead of commanding and controlling employees, managers would support them in reaching their full potential [8]. At the basis of McGregor's Theory Y are the expectations that employees are: (1) not innately lazy, (2) capable of self-direction and self-control, and (3) capable of providing significant ideas/proposals that will improve organizational efficiency [9]. Therefore, our executives need to adopt appropriate management practices, such as setting objectives and rewards and the chance to participate in decision making, this way personal and organizational goals can concurrently be realized [9].

\section{Conclusion}

From the above study one can conclude that from the growing entrepreneurials various negative factors arises. Therefore, various tools are designed to minimize various company negative factors like Ansoff's matrix, Macro-Environmental analysis, such as STEP, PEST, SERF and PESTLE, Porter's five-forces concept, Key/critical success factors and tools to maximize the involvement of people in our organizations through the use of Hertzberg's motivation theory, Maslow's hierarchy of needs, McGregor's theory x - theory y.

\section{References}

1. Petrilli MJ (2006) If the World Is Flat. Education Next, Cambridge

2. Watts G, Cope J, Hulme M (1998) Ansoff's Matrix, pain and gain Growth strategies and adaptive learning among small food producers. International Journal of Entrepreneurial Behaviour and Research 4:101-111.

3. Harvey MG, Novicevic MM (2006) The World is Flat: A Perfect Storm for Global Business? Organizational Dynamics 35: 207-219.

4. Dobbs ME (2014) Guidelines for applying Porter's five forces framework: a set of industry analysis templates. Competitiveness Review 24: 32-45.

5. Johnson M (2013) Critical success factors for B2B e-markets: a strategic fit perspective. Marketing Intelligence and Planning 31: 337-366.

6. Furnham A, Eracleous A, Chamorro-Premuzic T (2009) Personality, motivation and job satisfaction: Hertzberg meets the Big Five. Journal of Managerial Psychology 24: 765-779.

7. Carpenito-Moyet LJ (2003) Maslow's hierarchy of needs-revisited. Nursing Forum 38: 3-4

8. Weisbord M (2011)Taylor, McGregor and me. Journal of Management History 17: $165-177$

9. Kopelman RE, Prottas DJ, Davis AL (2008) Douglas McGregor's Theory X and Y: Toward a Construct-valid Measure. Journal of Managerial Issues 20: 255-271. 